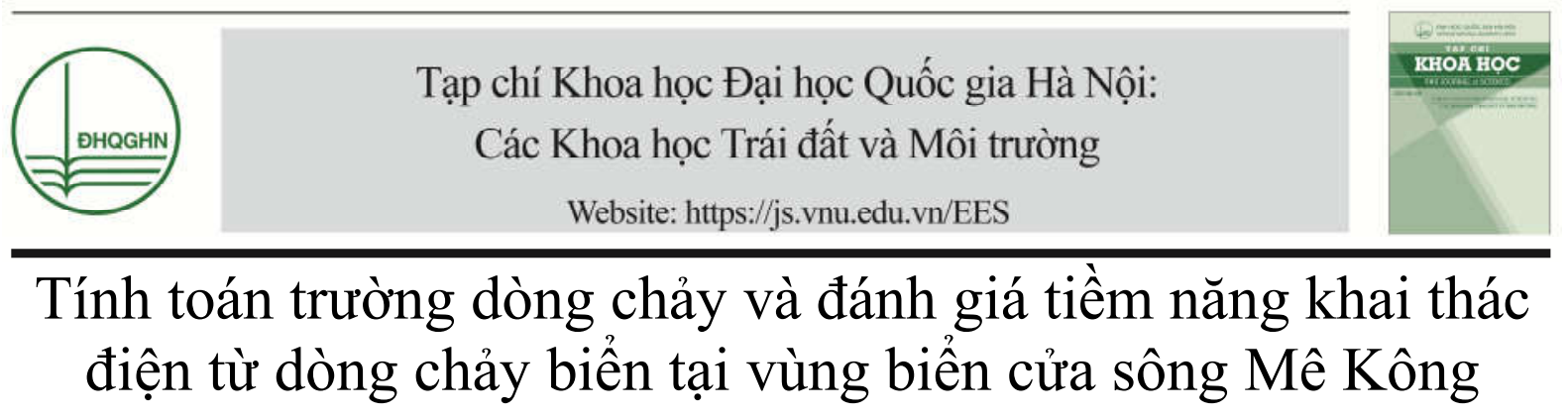

\author{
Vũ Thị Vui* \\ Khoa Khi tuợng Thủy văn và Hải dưong học, Truờng Đại học Khoa học Tự nhiên, ĐHQGHN, \\ 334 Nguyến Trãi, Thanh Xuân, Hà Nội, Việt Nam \\ Nhận ngày 30 tháng 11 năm 2018 \\ Chỉnh sửa ngày 12 tháng 12 năm 2018; Chấp nhận đăng ngày 25 tháng 12 năm 2018
}

\begin{abstract}
Tóm tắt: Khai thác năng lượng tái tạo từ biển là chủ đề rất được quan tâm những năm gần đây tại Việt Nam. Nhiều vùng biển ven bờ nước ta đã được khảo sát, đánh giá về khả năng khai thác năng lượng biển, tuy nhiên chưa có nghiên cứu nào quan tâm chi tiết về tiềm năng khai thác điện dòng chảy cho vùng biển cửa sông Mê Kông thuộc vùng biển ven bờ Đông Nam Bộ - nơi được đánh giá tốt về nguồn năng lượng từ dòng chảy biển. Nghiên cứu này có mục đích ước tính tiềm năng khai thác điện từ nguồn năng lượng dòng chảy biển cho vùng biển cửa sông Mê Kông nhờ việc tính toán trường dòng chảy tại vùng biển này bằng mô hình ROMS (Regional Ocean Modeling System) và thử nghiệm ước tính ứng dụng một trong các thiết bị tạo điện từ dòng chảy biển đang được nghiên cứu tại Việt Nam hiện nay. Kết quả tính cho thấy, tiềm năng khai thác điện tại vùng biển cửa sông Mê Kông là khả quan, với công suất điện năng đạt được lần lượt là trên $209 \mathrm{MWh}$ tại cửa sông, trên $116 \mathrm{MWh}$ tại Côn Đảo vào tháng 1 và trên $55 \mathrm{MWh}$ ở cả hai vị trí vào tháng 7 .
\end{abstract}

Tù khóa: Dòng chảy biển, năng lượng tái tạo, cửa sông Mê Kông, biển Đông Nam Bộ, ROMS.

\section{1. Đặt vấn đề}

Năng lượng phục vụ cho con người luôn là vấn đề cấp thiết. Trước thực trạng các nguồn năng lượng hóa thạch đang ngày càng cạn kiệt, năng lượng thủy điện hầu như đã được khai thác hết, năng lượng hạt nhân mang lại nhiều rủi ro,... thì các nguồn năng lượng tái tạo với các thế mạnh của mình đã và đang được chú trọng đầu tư nghiên cứu, khai thác. Các nguồn năng lượng tái tạo có nhiều ưu điểm: là nguồn năng lượng sạch, ít ảnh hưởng đến môi trường,

\footnotetext{
* Tác giả liên hệ. ĐT.: 84-902143446.

Email: vuivt@vnu.edu.vn

https://doi.org/10.25073/2588-1094/vnuees.4340
}

an toàn và quan trọng hơn cả, các nguồn năng lượng này có thể coi là vô tận.

Các nguồn năng lượng tái tạo đã được con người khai thác để tạo ra điện ở nhiều nơi trên thế giới có thể kể đển là năng lượng mặt trời, năng lượng gió, năng lượng địa nhiệt, năng lượng từ biển: sóng, dòng chảy, thủy triều, nhiệt biển, muối biển.Việt Nam cũng là một trong nhiều quốc gia khai thác được điện năng từ mặt trời. Đầu tháng 9 năm 2012, tại Bạc Liêu, 10 tua bin điện gió trên biển đầu tiên với tổng công suất $16 \mathrm{MW}$ đã được đấu nối vào lưới điện quốc gia, đưa Việt Nam vào danh sách các nước khai thác được điện từ gió. Tuy nhiên cho đến nay, Việt Nam chưa có một nhà máy điện nào sử dụng năng lượng biển, dù tiềm năng khai thác 
năng lượng biển của nước ta được đánh giá là khả quan. Theo Lê Đình Mầu và cs (2010), tốc độ dòng chảy có giá trị từ $0,3-3,0 \mathrm{~m} / \mathrm{s}$ là đủ để chứa nguồn năng lượng cực lớn, tổng năng lượng tiềm năng của dòng chảy biển trên thế giới có thể lên tới 5 tỷ $\mathrm{KW}$. Theo nhóm tác giả này, dải ven biển Nam Trung Bộ được đánh giá là có tiềm năng phát triển điện dòng chảy nhất cả nước, tuy nhiên các vị trí có sóng lớn, dòng chảy mạnh đều nằm tại các mũi đá nhô ra biển làm tăng chi phí khai thác [1].

Với mục đích ước tính tiềm năng khai thác điện từ nguồn năng lượng dòng chảy biển cho vùng biển cửa sông Mê Kông và Côn Đảo nhằm đáp ứng nhu cầu điện năng cho khu vực này đồng thời có khả năng làm giảm ảnh hưởng của xâm nhập mặn lên đồng bằng sông Cửu Long, nghiên cứu ở đây tập trung tính toán trường dòng chảy tại vùng biển cửa sông Mê Kông bằng mô hình ROMS (Regional Ocean Modeling System) để đưa ra các thông tin cần thiết làm đầu vào cho việc thử nghiệm ứng dụng một trong các thiết bị tạo điện từ dòng chảy biển đang được nghiên cứu tại Việt Nam là mô hình máy phát điện bằng dòng hải lưu của KS Doãn Mạnh Dũng [2].

\section{Phương pháp nghiên cứu và nguồn số liệu sử dụng}

\subsection{Giới thiệu hệ thống mô hình ROMS}

Theo D.B. Haidvogel và cs (2008), ROMS là mô hình ba chiều được nghiên cứu và phát triển bởi Đại học California, Đại học Rutgers (Hoa Kỳ) và tổ chức IRD (Pháp). ROMS giải các phương trình thủy động lực thủy tĩnh và bề mặt tự do cho các địa hình phức tạp, trên hệ lưới cong trực giao theo phương ngang và tọa độ sigma thích ứng địa hình theo phương thẳng đứng. Theo đó sơ đồ sai phân trung tâm bậc hai trên lưới Arakawa-C được sử dụng cho phương ngang với các điều kiện biên trượt tự do, trượt một phần hoặc điều kiện dính, theo phương thẳng đứng sử dụng sai phân xen kẽ bậc hai.

Nghiên cứu này sử dụng phiên bản ROMS AGRIF được phát triển bởi tổ chức IRD (Pháp) [3], được hỗ trợ bởi bộ công cụ ROMSTOOLS xử lý thông tin vào/ra cho các quá trình trước và sau chạy mô hình. Nhân thủy động lực của ROMS giải hệ phương trình NavierStokes trung bình Reynolds, sử dụng xấp xỉ Boussinesq và xấp xỉ thủy tĩnh. Hệ các phương trình nguyên thủy của ROMS như sau:

$$
\begin{gathered}
\frac{\partial\left(H_{Z} u\right)}{\partial t}+\frac{\partial\left(u H_{Z} u\right)}{\partial x}+\frac{\partial\left(v H_{Z} u\right)}{\partial y}+\frac{\partial\left(\Omega H_{Z} u\right)}{\partial \sigma}-f H_{Z} v=-\frac{H_{Z}}{\rho_{0}} \frac{\partial p}{\partial x}-H_{Z} g \frac{\partial \zeta}{\partial x}-\frac{\partial}{\partial \sigma}\left(\overline{u^{\prime} w^{\prime}}-\frac{v}{H_{Z}} \frac{\partial u}{\partial \sigma}\right) \text { (1) } \\
\frac{\partial\left(H_{Z} v\right)}{\partial t}+\frac{\partial\left(u H_{Z} v\right)}{\partial x}+\frac{\partial\left(v H_{Z} v\right)}{\partial y}+\frac{\partial\left(\Omega H_{Z} v\right)}{\partial \sigma}+f H_{Z} u=-\frac{H_{Z}}{\rho_{0}} \frac{\partial p}{\partial y}-H_{Z} g \frac{\partial \zeta}{\partial y}-\frac{\partial}{\partial \sigma}\left(\overline{v^{\prime} w^{\prime}}-\frac{v}{H_{Z}} \frac{\partial v}{\partial \sigma}\right) \text { (2) } \\
0=-\frac{1}{\rho_{0}} \frac{\partial p}{\partial \sigma}-\frac{g}{\rho_{0}} H_{z} \rho \text { (3) } \frac{\partial \zeta}{\partial t}+\frac{\partial\left(H_{Z} u\right)}{\partial x}+\frac{\partial\left(H_{Z} v\right)}{\partial y}+\frac{\partial\left(H_{Z} \Omega\right)}{\partial \sigma}=0 \text { (4) } \rho=f(T, S, p) \text { (5) } \\
C \frac{\partial\left(H_{Z} C\right)}{\partial t}+\frac{\partial\left(u H_{Z} C\right)}{\partial x}+\frac{\partial\left(v H_{Z} C\right)}{\partial y}+\frac{\partial\left(\Omega H_{Z} C\right)}{\partial \sigma}=-\frac{\partial}{\partial \sigma}\left(\overline{C^{\prime} w^{\prime}}-\frac{k}{H_{Z}} \frac{\partial C}{\partial \sigma}\right)+C_{\text {source }} \text { (6) }
\end{gathered}
$$

trong đó: $u, v, \Omega$ tương ứng là thành phần vận tốc theo các phương $x, y, \sigma ; \zeta v a ̀$ a $h$ cao độ mặt thoáng và đáy biển; $H_{Z}$ - hệ số tỷ lệ theo phương đứng; $f$ - tham số Coriolis; $g$ - gia tốc trọng trường; $v$ - hệ số nhớt và $k$ - hệ số khuếch tán; $\rho$ và $\rho_{0}$ - mật độ và mật độ chuẩn; $T, S$ và $p$ -nhiệt độ, độ muối và áp suất; $C$ và $C_{\text {sourse }}$ nồng độ (hoặc sinh khối) và nguồn $\sinh /$ mất của các yếu tố vô hướng (như nhiệt, muối, các chất hòa tan, lơ lửng hay sinh vật nổi...); gạch ngang ở trên - biểu thị lấy trung bình thời gian; dấu nháy (') - nhiễu động rối.

Khép kín rối được thực hiện nhờ tham số hóa ứng suất Reynolds và thông lượng rối với sự có mặt của hệ số nhớt xoáy động lượng $\left(K_{M}\right)$ và hệ số khuếch tán $\left(K_{H}\right)$ : 


$$
\overline{u^{\prime} w^{\prime}}=-K_{M} \frac{\partial u}{\partial z}(\mathbf{7}) ; \overline{v^{\prime} w^{\prime}}=-K_{M} \frac{\partial v}{\partial z} \text { (8) } \overline{C^{\prime} w^{\prime}}=-K_{H} \frac{\partial \rho}{\partial z} \text { (9) }
$$
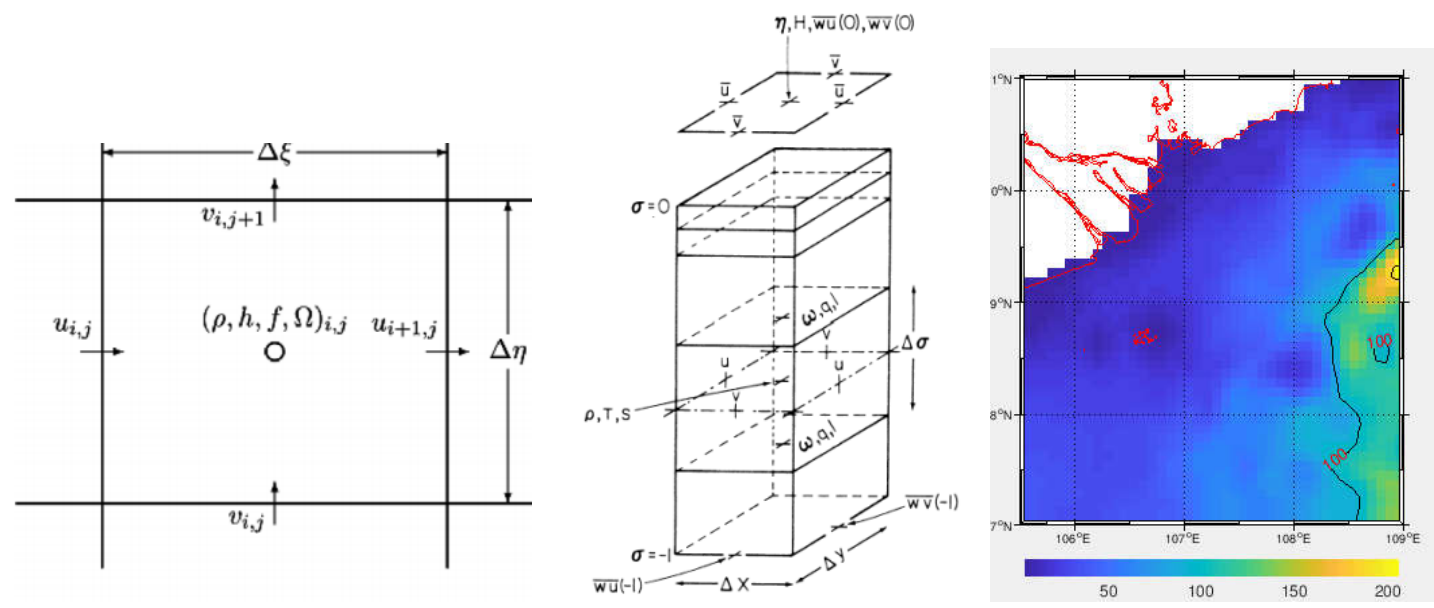

Hình 1. Trái: sơ đồ lưới Arakawa-C theo phương ngang Phải: lưới ROMS theo phương thẳng đứng theo

Hình 2. Địa hình và lưới tính của khu vực D.B. Haidvogel và cs (2008).

\subsection{Nguồn số liệu sủ dụng}

Địa hình miền tính được lấy từ nguồnsố liệu ETOTO2 có độ phân giải 2 phút; các yếu tố khí tượng tạo đầu vào lực tác động được lấy từ nguồnsố liệu COADS05 (số liệu toàn cầu trung bình tháng các thông lượng khí tượng bề mặt biển); các yếu tố hải văn tạo điều kiện biên và ban đầu được lấy từ nguồn số liệu WOA2009 (số liệu toàn cầu trung bình tháng các yếu tố thủy văn biển) [4]; Nguồn số liệu thủy triều làbộ số liệu hằng số điều hòa thủy triều TPXO7 được xử lý từ bộ số liệu thủy triều OSU, dùng làm điều kiện để tính lan truyền triều từ biên, với 10 hằng số điều hòa của các sóng chính: $\mathrm{M}_{2}, \mathrm{~S}_{2}, \mathrm{~N}_{2}, \mathrm{~K}_{2}, \mathrm{~K}_{1}, \mathrm{O}_{1}, \mathrm{P}_{1}, \mathrm{Q}_{1}, \mathrm{M}_{\mathrm{f}}, \mathrm{M}_{\mathrm{m}}$. Mô hình tính từ ngày $1 / 1 / 2018$ đến ngày $31 / 7 / 2018$ với bước thời gian 900 s.

\subsection{Phạm vi nghiên cứu và luới tính}

Nghiên cứu này sử dụng miền tính: kinh độ: $105.5^{0} \mathrm{E}-109^{0} \mathrm{E}$; vĩ độ: $15^{0} \mathrm{~N}-19^{0} \mathrm{~N}$. Lưới tính có độ phân giải $1 / 12^{0}$ (khoảng $9 \mathrm{~km}$ ), chia thành 10 tầng sigma (hình 3 ).

\subsection{Thiết bị tạo điện tì̀ dòng chảy biển}

Thiết bị tạo điện từ dòng chảy biển được sử dụng trong nghiên cứu này là mô hình máy phát điện bằng dòng hải lưu được Doãn Mạnh Dũng (2018) thiết kế và phát triển [2]. Theo thiết kế của Doãn Mạnh Dũng (2018), một khối máy phát điện gọi là một mô-đun, có kích thước thiết kế cho việc khai thác dòng hải lưu có độ sâu $20 \mathrm{~m}$ với chiều rộng $32 \mathrm{~m}$, chiều dài $34.5 \mathrm{~m}$, chiều cao kể cả thượng tầng là $35 \mathrm{~m}$. Một môđun máy phát điện có 7 trục tuốc bin. Mỗi trục turbine có 15 cửa tiếp nhận năng lượng. Mỗi cửa có 1 mô-đun cánh quạt. Mỗi mô-đun cánh quạt có 3 nón tiếp nhận động năng hình chóp nón với đường kính $1 \mathrm{~m}$. Máy phát điện sử dụng động năng dòng thủy lực theo mô hình đón năng lượng bằng hệ cánh quạt hình chuông như máy đo gió [2] (hình 3). Nghiên cứu này sử dụng bộ thiết bị giả định được thiết kế cho vùng nước nông hơn với hai tầng nước: tầng $3 \mathrm{~m}$ và tầng $7 \mathrm{~m}$. 

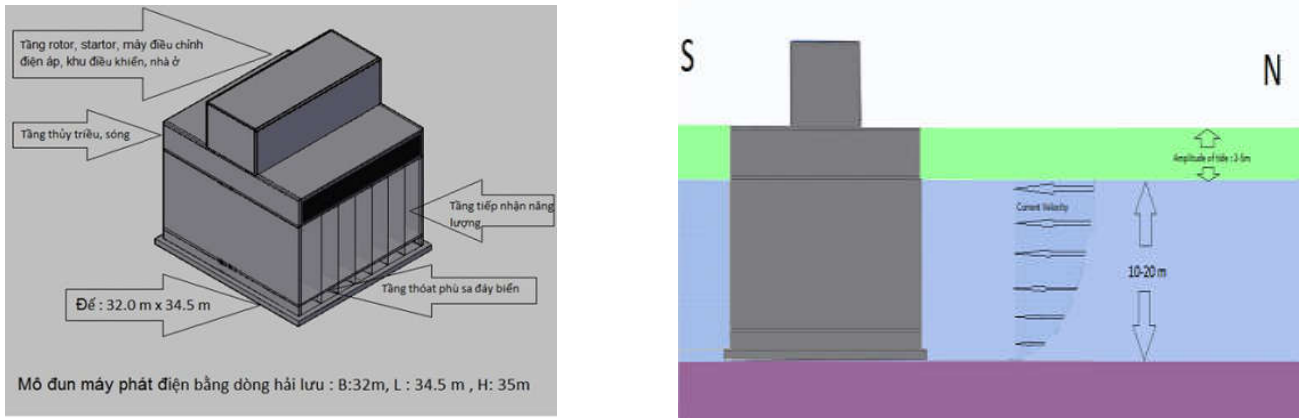

Hình 3. Mô đun máy phát điện và phân bố véc tơ tốc độ dòng chảy tác động vào máy phát điện [2].

Các công thức tính công suất từ động năng sang điện năng với hệ số hiệu suất $60 \%$ theo nguyên tắc bảo toàn năng lượng như sau [2]:

$\mathrm{W}=0.5 \mathrm{mv}^{2}$ (10)

Trong đó:

m: khối lượng của vật di chuyển $(\mathrm{kg})$

$\mathrm{v}$ : tốc độ của vật di chuyển $(\mathrm{m} / \mathrm{s})$

W: động năng của vật di chuyển (Ws)

Khi dòng chảy gặp chuông, một khối lượng nước $\mathrm{m}$ như sau đã tác động vào mặt chuông có bán kính $\mathrm{r}$ trong 1 giây:

Trong đó

$$
\mathrm{m}=1034 . \pi \cdot \mathrm{r}^{2} \cdot \mathrm{v}(\mathrm{kg}) \mathbf{( 1 1 )}
$$

$1 \mathrm{~m}^{3}$ nước biển $=1000 \times 1.034=1034 \mathrm{~kg}$

$\mathrm{r}=0.5 \mathrm{~m}$ - bán kính của chuông

v: tốc độ của dòng chảy $(\mathrm{m} / \mathrm{s})$

$$
\pi=3.1416 \text { - số } \mathrm{Pi}
$$

Động năng chuyển từ dòng chảy thành điện năng trong 1 giây là công suất của một cánh quạt.

Trong đó

$$
\mathrm{N}=\mathrm{k} 0.5 \mathrm{~m} \mathrm{v}^{2}(\mathbf{1 2})
$$

$\mathrm{k}=0.6$ - hệ số giả định chuyển đổi từ động năng sang điện năng.

\section{Kết quả và thảo luận}

\subsection{Truờng dòng chảy trung bình năm tại vùng biển cứa sông Mê Kông}

Kết quả trường dòng chảy vùng biển cửa sông Mê Kông được sử dụng là trường dòng chảy tháng 1 và tháng 7 , đại diện cho hai mùa gió tương ứng là mùa gió Đông Bắc và mùa gió Tây Nam. Hình 4 thể hiện kết quả trường dòng chảy tầng mặt, tầng $3-5-7 \mathrm{~m}$ lúc $0 \mathrm{~h}$ ngày 15/1/2018- mùa gió Đông Bắc tại vùng biển cửa sông Mê Kông. Kết quả cho thấy: Vào thời kỳ mùa đông, chịu ảnh hưởng của gió mùa Đông Bắc, dòng chảy vùng biển ven bờ Đông Nam Bộ có hướng chủ đạo là hướng Tây Nam, dao động trong khoảng $0.02-0.63 \mathrm{~m} / \mathrm{s}$, với tốc độ đạt cực đại có thể lên đến trên $0.6 \mathrm{~m} / \mathrm{s}$. Vùng cửa sông Mê Kông sát bờ xuất hiện một cực đại dòng chảy đạt trên $0.6 \mathrm{~m} / \mathrm{s}$. Khu vực Côn đảo cũng xuất hiện một cực đại dòng chảy đạt trên $0.5 \mathrm{~m} / \mathrm{s}$.

Kết quả trường dòng chảy tầng mặt, tầng 3$5-7 \mathrm{~m}$ lúc $12 \mathrm{~h}$ ngày $22 / 7 / 2018$ - mùa gió Tây Nam tại vùng biển cửa sông Mê Kông (hình 5) cho thấy: Vào thời kỳ mùa hè, chịu tác động của gió mùa Tây Nam, dòng chảy chủ đạo của vùng biển ven bờ Đông Nam Bộ có hướng Đông Bắc, dao động trong khoảng $0.01-0.4$ $\mathrm{m} / \mathrm{s}$, với tốc độ đạt cực đại có thể lên đến trên $0.4 \mathrm{~m} / \mathrm{s}$. Vùng cửa sông Mê Kông sát bờ cũng xuất hiện một cực đại dòng chảy đạt trên 0.4 $\mathrm{m} / \mathrm{s}$, dồng thời tại khu vực quanh Côn Đảo cũng tồn tại một cực đại dòng chảy đạt trên $0.4 \mathrm{~m} / \mathrm{s}$. Kết hợp với trường dòng chảy tháng 1 ở trên, có thể thấy đây là một kết quả đáng chú ý để cân nhắc đặt hệ thống phát điện tại hai khu vực này, đặc biệt là khu vực Côn Đảo - nơi cần thiết có hệ thống phát điện riêng.

Từ hai khu vực xuất hiện cực đại tốc độ dòng chảy ở cả hai mùa tại vùng cửa sông sát bờ và Côn Đảo, trích xuất số liệu dòng chảy và tính trung bình giờ tại một vi trí đạt cực đại để sử dụng cho việc ước tính tiềm năng khai thác điện tại hai khu vực này. 

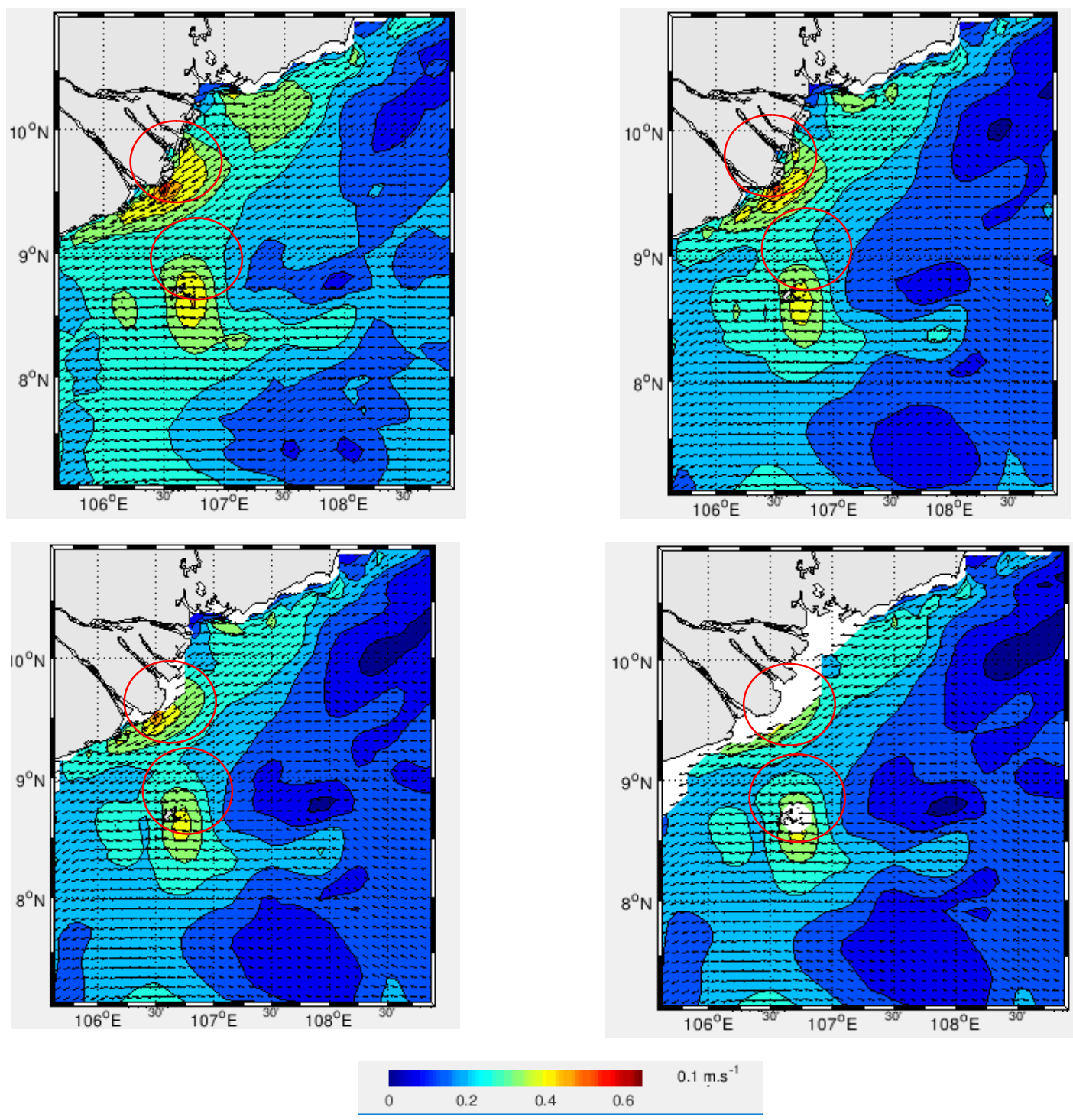

Hình 4. Trường dòng chảy $0 \mathrm{~h}$ ngày $15 / 1 / 2018$ :

Hàng trên: tầng mặt (trái) và tầng $3 \mathrm{~m}$ (phải), Hàng dưới: tầng $5 \mathrm{~m}$ (trái) và tầng $7 \mathrm{~m}$ (phải) tại vùng biển cửa sông Mê Kông.

\section{2. Đánh giá tiềm năng khai thác điện tù̀ dòng chảy biển}

Từ kết quả trích xuất tại hai khu vực quan tâm, với giả thiết đặt máy phát điện tại đó, có thể đưa ra hai giá trị trung bình giờ tốc độ dòng chảy tương ứng đi qua hai nhóm cánh quạt của bộ máy phát điện. Qua đó, theo công thức (12), có thể đưa ra ước tính khả năng khai thác điện tại vùng biển cửa sông Mê Kông với giả thiết sử dụng 20 mô đun máy phát điện như bảng 1 . Các kết quả tính toán cho thấy vùng biển cửa sông Mê Kông có tiềm năng khai thác điện năng tương đối tốt khi so sánh với các loại hình phát điện từ thủy điện hoặc nhiệt điện: trên 209 MWh tại cửa sông, trên $116 \mathrm{MWh}$ tại Côn Đảo vào tháng $1 / 2018$ và trên $55 \mathrm{MWh}$ ở cả hai vị trí vào tháng $7 / 2018$, với công suất tổng cộng 
tại khu vực cửa sông: đạt gần $156.000 \mathrm{MW}$ vào tháng 1 và trên $41.000 \mathrm{MW}$ vào tháng 7 , còn tại Côn Đảo: đạt trên $86.000 \mathrm{MW}$ vào tháng 1 và cũng trên $41.000 \mathrm{MW}$ vào tháng 7 . Giá trị khai thác càng lớn khi đặt hệ thống nhiều mô đun. Đặc biệt, vị trí khai thác điện năng sát bờ đem đến nhiều thuận lợi cho việc xây dựng và truyền tải điện, đồng thời, rất có thể việc khai thác năng lượng dòng chảy sẽ góp phần làm giảm hiện tượng xâm nhập mặn đang gây đau đầu
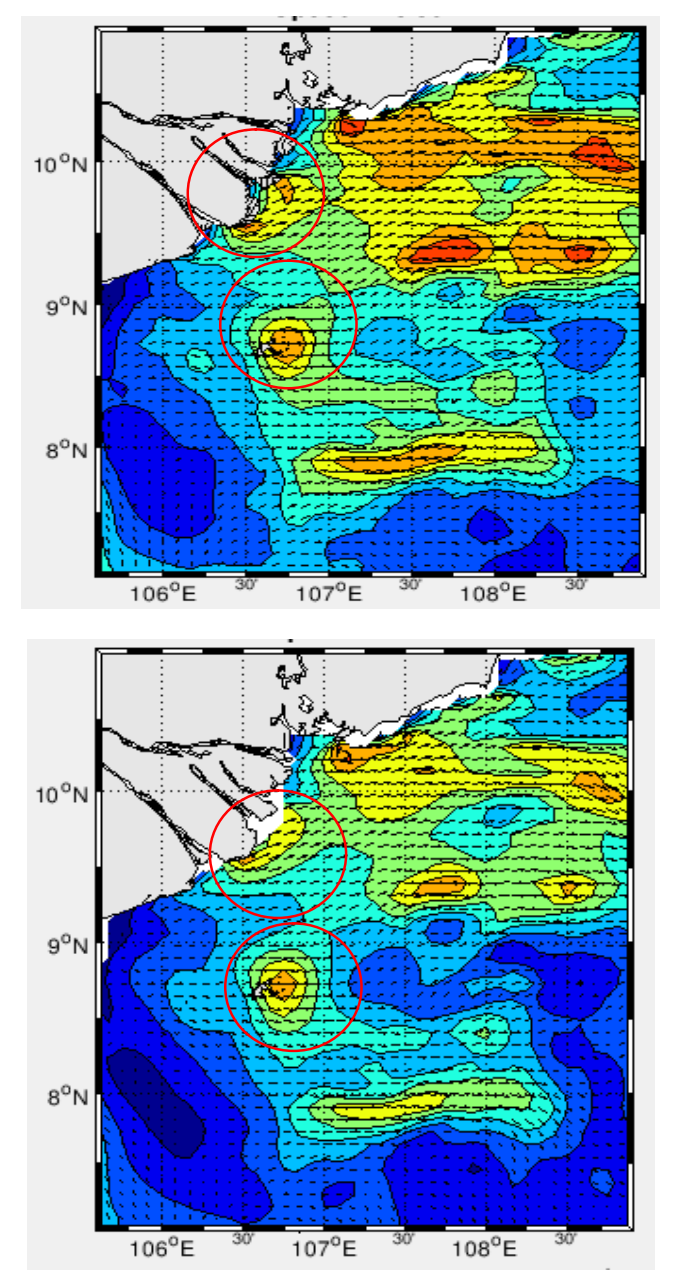

cho các nhà quản lý, các nhà khoa học và người dân nơi đây. Còn tại vị trí Côn Đảo, khai thác điện năng dòng chảy ở khu vực này là một điều rất cần thiết, việc xây dựng một hệ thống phát điện riêng từ biển tại khu vực này mang lại nhiều giá trị kinh tế-xã hội. Tuy nhiên, việc tính toán và ứng dụng bộ máy phát điện còn ở giai đoạn thử nghiệm, trên lý thuyết, rất cần có thêm thực tiễn để chứng minh.
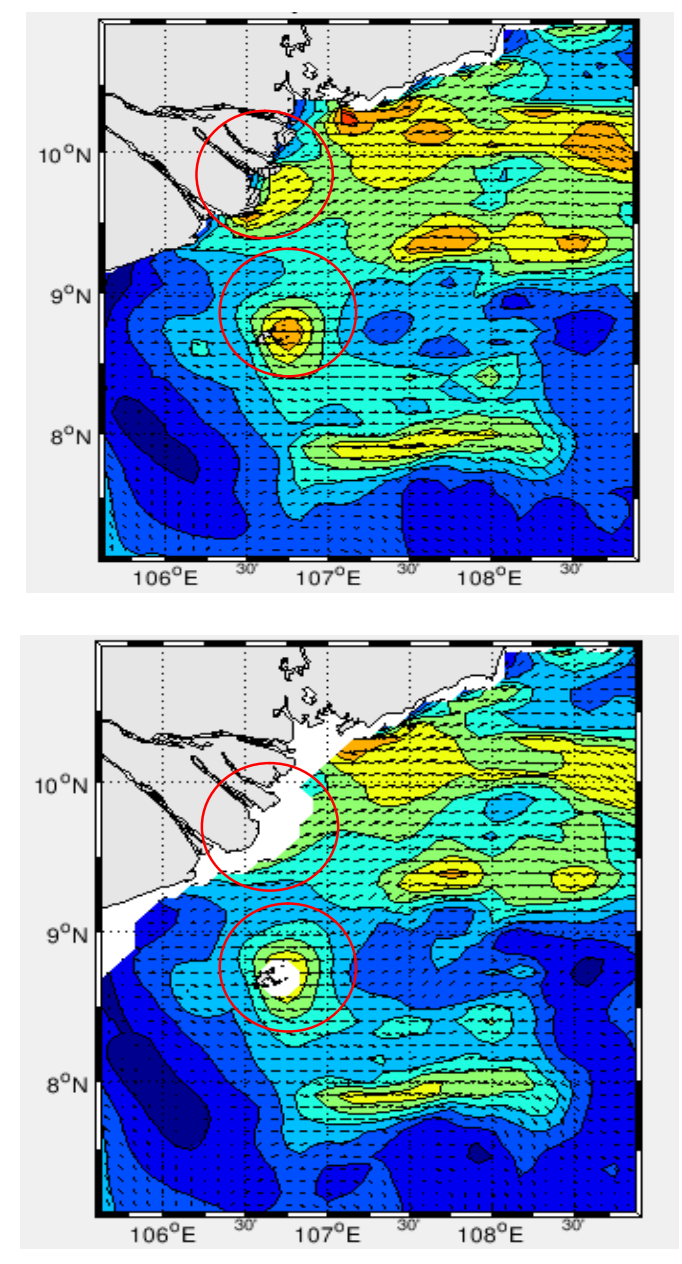

$0.1 \mathrm{~m} \cdot \mathrm{s}^{-1}$

Hình 5. Trường dòng chảy $12 \mathrm{~h}$ ngày $22 / 7 / 2018$ :

Hàng trên: tầng mặt (trái) và tầng $3 \mathrm{~m}$ (phải), Hàng dưới: tầng $5 \mathrm{~m}$ (trái) và tầng $7 \mathrm{~m}$ (phải) tại vùng biển cửa sông Mê Kông 
Bảng 1. Ước tính tiềm năng khai thác điện dòng chảy tại ven bờ cửa sông Mê Kông và Côn Đảo

\begin{tabular}{|c|c|c|c|c|}
\hline \multirow{2}{*}{$\begin{array}{l}\text { Vị trí cửa sông } \\
\text { Mê Kông }\end{array}$} & \multicolumn{2}{|c|}{ Mùa gió Đông Bắc } & \multicolumn{2}{|c|}{ Mùa gió Tây Nam } \\
\hline & $\begin{array}{l}\text { Tốc độ dòng chảy (được } \\
\text { tính trung bình giờ) } \\
(\mathrm{m} / \mathrm{s})\end{array}$ & $\begin{array}{l}\text { Công suất } \\
\text { (MWh) }\end{array}$ & $\begin{array}{l}\text { Tốc độ dòng chảy (được } \\
\text { tính trung bình giờ) } \\
(\mathrm{m} / \mathrm{s})\end{array}$ & $\begin{array}{l}\text { Công suất } \\
\text { (MWh) }\end{array}$ \\
\hline $\begin{array}{l}\text { Nhóm } 5 \text { cánh } \\
\text { quạt tầng trên }\end{array}$ & 0,6 & 0.947 & 0,4 & 280.663 \\
\hline $\begin{array}{l}\text { Nhóm } 5 \text { cánh } \\
\text { quạt tầng dưới }\end{array}$ & 0,5 & 0.548 & 0,3 & 118.405 \\
\hline $\begin{array}{l}\text { Tồng cộng } 1 \\
\text { tuốc bin }\end{array}$ & & 1,495 & & 0,399 \\
\hline $\begin{array}{l}\text { Tổng cộng } 1 \text { mô } \\
\text { đun ( } 7 \text { tuốc bin) }\end{array}$ & & 10,465 & & 2,793 \\
\hline $\begin{array}{l}\text { Tổng cộng } 20 \\
\text { mô đun }\end{array}$ & & 209,3 MWh & & 55,86 \\
\hline $\begin{array}{l}\text { Tổng cộng tháng } \\
\text { ( } 744 \text { giờ) }\end{array}$ & & 155.719 MW & & $41.560 \mathrm{MW}$ \\
\hline \multirow[t]{2}{*}{ Vị trí Côn Đảo } & \multicolumn{2}{|c|}{ Mùa gió Đông Bắc } & \multicolumn{2}{|c|}{ Mùa gió Tây Nam } \\
\hline & $\begin{array}{l}\text { Tốc độ dòng chảy (được } \\
\text { tính trung bình giờ) } \\
(\mathrm{m} / \mathrm{s})\end{array}$ & $\begin{array}{l}\text { Công suất } \\
\text { (MWh) }\end{array}$ & $\begin{array}{l}\text { Tốc độ dòng chảy (được } \\
\text { tính trung bình giờ) } \\
(\mathrm{m} / \mathrm{s})\end{array}$ & $\begin{array}{l}\text { Công suất } \\
\text { (MWh) }\end{array}$ \\
\hline $\begin{array}{l}\text { Nhóm cánh quạt } \\
\text { tầng trên }\end{array}$ & 0.5 & 0,548 & 0.4 & 0,281 \\
\hline $\begin{array}{l}\text { Nhóm cánh quạt } \\
\text { tầng dưới }\end{array}$ & 0.4 & 0,281 & 0.3 & 0,118 \\
\hline $\begin{array}{l}\text { Tổng cộng } 1 \\
\text { tuốc bin }\end{array}$ & & 0,829 & & 0,399 \\
\hline $\begin{array}{l}\text { Tổng cộng } 1 \text { mô } \\
\text { đun (7 tuốc bin) }\end{array}$ & & 5,803 & & 2,793 \\
\hline Tổng cộng 20 & & & & 55,86 \\
\hline $\begin{array}{l}\text { mô đun } \\
\text { Tổng công tháng }\end{array}$ & & 116,06 & & \\
\hline (744 giờ) & & $86.348 \mathrm{MW}$ & & $41.560 \mathrm{MW}$ \\
\hline
\end{tabular}

\section{Kết luận}

Kết quả ứng dụng mô hình thủy động lực ROMS tại vùng biển cửa sông Mê Kông cho thấy:

Thời kỳ mùa đông, dòng chảy vùng biển ven bờ Đông Nam Bộ có hướng chủ đạo là hướng Tây Nam, dao động trong khoảng $0.02-$ $0.6 \mathrm{~m} / \mathrm{s}$, với tốc độ đạt cực đại có thể lên đến trên $0.6 \mathrm{~m} / \mathrm{s}$ còn thời kỳ mùa hè, tốc độ dòng chảy dao động trong khoảng $0.01-0.4 \mathrm{~m} / \mathrm{s}$, với tốc độ đạt cực đại có thể lên đến trên $0.4 \mathrm{~m} / \mathrm{s}$. Cả hai mùa đều cho thấy tồn tại hai vị trí cực đại tốc độ dòng chảy: khu vực sát bờ và Côn
Đảo, từ đó có thể giả thiết đặt bộ máy phát điện ở hai vị trí này.

Kết quả tính toán công suất tạo điện năng theo giả thiết cho thấy vùng biển cửa sông Mê Kông có tiềm năng khai thác điện năng tương đối tốt khi so sánh với nhiều loại hình khai thác khác như thủy điện hay nhiệt điện (hơn 209 $\mathrm{MWh}$ vào mùa gió Đông Bắc và trên $55 \mathrm{MWh}$ vào mùa gió Tây Nam).Vị trí khai thác điện tiềm năng có thể đặt tại Côn Đảo đem lại nhiều thuận lợi. Tuy nhiên, việc ước tính trong nghiên cứu này mới chỉ ở giai đoạn thử nghiệm, cần có các nghiên cứu thực nghiệm sâu hơn. 


\section{Lời cảm ơn}

Tác giả là NCS thuộc đề án 911 nên được nhận sự tài trợ cho nghiên cứu này từ đề án. Tác giả xin cảm ơn sự tài trợ này.

\section{Tài liệu tham khảo}

[1] Lê Đình Mầu, Nguyễn Bá Xuân, 2010, "Khái quát về năng lượng biển và bước đầu đánh giá tiềm năng của chúng tại Việt Nam”, Tuyển tập Nghiên cứu biển, XVII, tr. 199-206.

[2] Doãn Mạnh Dũng, 2015, "Ý tưởng dùng dòng hải lưu để phát điện", Báo khoa học Phổ thông số $50 / 14$ (1652) ngày 2/1/2015 (được cập nhật ngày 16/01/2018 trên website kinhtebien.vn).

[3] Pierrick Penven, Gildas Cambon, Thi-Anh Tan, Patrick Marchesiello and Laurent Debreu, 2010, ROMS AGRIF/ROMSTOOLS User's Guide, Institut de Recherche pour le D'eveloppement (IRD), France.

[4] Website: https://www.croco-ocean.org/

\title{
Estimating the Sea Current Field and Assessing the Potential for Exploiting Electricity from the Sea Current in the Estuary of the Mekong River
}

\author{
Vu Thi Vui \\ Faculty of Hydro-Meteology \& Oceanography, VNU University of Science, \\ 334 Nguyen Trai, Thanh Xuan, Hanoi, Vietnam
}

\begin{abstract}
Exploiting renewable energy from the sea is a topic of great interest in recent years in Vietnam. Many coastal areas of our country have been surveyed to assess the potential of marine energy exploitation. However, there have been no studies detailing the potential of exploiting the sea current energy in the Mekong River mouth. This study aims to estimate the potential of marine power generation for the Mekong River mouth by calculating the ocean current flow using the Regional Ocean Modeling System (ROMS). It is estimated following one of the marine electricity generation equipment is being studied in Vietnam. The results show that the potential for power exploitation in the Mekong River mouth is positive, with total capacity reaching over $209 \mathrm{MWh}$ at the river mouth, above 116 MWh in Con Dao in January and above 55 MWh in both locations in July in 2018.
\end{abstract}

Keywords: Ocean currents, recycled energy, Mekong estuary, South East sea, ROMS. 